\title{
A comparative study of growth, biological efficiency, antioxidant activity and molecular structure in wild and commercially cultivated Auricularia cornea strains
}

\author{
Asif Ali Khan ${ }^{1}$, Fangjie Yao ${ }^{1, *}$, Muhammad Idrees ${ }^{1}$, Lixin Lu ${ }^{2}$, Ming Fang', \\ Peng Wang ${ }^{1}$, Wan-Zhu Jiang ${ }^{1}$, You Min Zhang ${ }^{2, *}$
}

\footnotetext{
${ }^{1}$ Engineering Research Center of Chinese Ministry of Education for Edible and Medicinal Fungi, Jilin Agricultural University, Changchun 130118, P. R. China

${ }^{2}$ College of Horticulture, Jilin Agricultural University, Changchun 130118, P. R. China
}

\begin{abstract}
Auricularia cornea, jelly mushroom, is a popular ingredient of traditional Chinese cuisine. This study aimed at evaluating the growth, yield, biological efficiency, total phenolic and flavonoid contents, the antioxidant activity, elemental composition, and molecular structure of the wild and domesticated strain Ac24 and the commercially cultivated edible mushroom A. cornea strains Ac1, Ac3 and Ac15. Based on the weight of the fresh fruiting bodies of A. cornea strains, the maximum yield was obtained from commercial strain Ac1 (237.10 g), followed by Ac3 (224.47 g), Ac15 (158 g) and Ac24 (132.37 g), while the biological efficiency range of $A$. cornea strains was 52.94-94.84\%, with significant differences among the $A$. cornea strains. Our results revealed that Ac24 contained the highest phenolic content $\left(20.10 \mathrm{mg} \mathrm{GAE} \cdot \mathrm{g}^{-1}\right)$, while the highest flavonoid content was found in Ac1 $\left(35.13 \mathrm{mg} \mathrm{CE} \cdot \mathrm{g}^{-1}\right)$. The maximum mineral contents and the strains were as follows: copper $\left(7.2 \mathrm{mg} \cdot \mathrm{kg}^{-1}\right)$ and zinc $\left(310 \mathrm{mg} \cdot \mathrm{kg}^{-1}\right)$ in Ac1, manganese $\left(788 \mathrm{mg} \cdot \mathrm{kg}^{-1}\right)$ in Ac3 and iron $\left(310 \mathrm{mg} \cdot \mathrm{kg}^{-1}\right)$ in Ac24. DPPH assay found maximum antioxidant activity in Ac24 $\left(\mathrm{IC}_{50} 0.233 \mathrm{mg} \mathrm{TX} \cdot \mathrm{mL}^{-1}\right)$, FRAP $\left(591 \mathrm{mg} \mathrm{TX} \cdot \mathrm{g}^{-1}\right)$ in Ac15, and erythrocyte haemolysis in Ac24. SEM-EDX and FTIR analyses verified the differences among $A$. cornea strains. The results revealed that wild, domesticated A. cornea strain Ac24 is a promising dietary source of natural antioxidants and is of high nutritional value, compared to commercially cultivated strains.
\end{abstract}

Keywords: antioxidant, Auricularia cornea, energy-dispersive x-ray, Fourier-transform infrared spectroscopy, scanning electron microscopy

\section{INTRODUCTION}

Auricularia cornea belongs to Family Auriculariaceae under Division Basidiomycota. This is an edible fungus with high nutritional value, as its fruiting bodies are abundant in amino acids, polysaccharides, vitamins and minerals (Sheu et al., 2004). Auricularia cornea is widely used as a functional food and oriental stimulant, especially in Korea and China (Abd Razak et al., 2013). Due to its significant medicinal value and high economic returns, the cultivation area of A. cornea and Auricularia heimuer is continuously increasing, especially in China, with an annual production of about 8 million tons in the past 5 years. A variety of agro-industrial wastes, such as cotton waste, wheat straw and sawdust, can be utilised to cultivate A. cornea (Ghorai et al., 2009; Sánchez, 2010; Zhang et al., 2016; Dai et al., 2019). 
Contemporary pharmacological studies have revealed that $A$. cornea has anti-nociceptive functions, reduces blood fat, and has anti-tumour property and aphrodisiac activity (Yang et al., 2002; Arora et al., 2013; Gupta et al., 2018). Moreover, A. cornea can also nourish the lungs so that it breathes easily, enriches and circulates blood, and restrains pain and bleeding (Song and Du, 2012). Recently, A. cornea was shown to exhibit hypoglycaemic effect by reducing blood glucose levels, modulating glucose tolerance and recovering the serum level in experimental mice (Wang et al., 2019). Based on the massive data reporting its medicinal values, $A$. cornea can be exploited as an antioxidant and antimicrobial agent.

Oxidation is a natural process in which energy is produced by living organisms. Recent studies have revealed that numerous bioactive compounds obtained from biological sources play a crucial role in the prevention of oxidative mutilation in living organisms by free radical-scavenging and might serve as innovative potential antioxidants (Matkowski et al., 2008; Yuan et al., 2008). Similarly, the ethyl acetate and aqueous extracts of $A$. cornea showed high efficiency as antioxidants in scavenging all kinds of radicals (Cai et al., 2015). However, knowledge about the antioxidant potential of Chinese germplasm resources of $A$. cornea is scarce. The present study was designed to evaluate the phenolic and flavonoid contents, antioxidant activity, elemental composition and molecular structure of a wild domesticated and commercially cultivated strains of A. cornea from China.

\section{MATERIALS AND METHODS}

\section{Mushroom strains and cultivation experiment}

Four strains of $A$. cornea were used in this study (Table 1 and Figure 1). Three commercial strains were obtained from the Mushroom Breeding and Genetics Laboratory, the Engineering Research Centre for Edible and Medicinal Fungi, Jilin Agricultural University, Changchun, while one wild strain was collected by Prof. Yao Fangjie from the Dashushan Forest Park, Hefei City, Anhui Province, China, and then domesticated in the Mushroom Breeding and Genetics Laboratory. The multiplication of $A$. cornea strains was performed on potato dextrose agar medium (PDA; $200 \mathrm{~g} \cdot \mathrm{L}^{-1}$ chopped potatoes, $12 \mathrm{~g} \cdot \mathrm{L}^{-1}$ agar, $20 \mathrm{~g} \cdot \mathrm{L}^{-1}$ glucose) at $25-26^{\circ} \mathrm{C}$ for regular subculture and maintained on PDA slants at $4^{\circ} \mathrm{C}$. The sawdust spawn was prepared in $800 \mathrm{~mL}$ polypropylene plastic bottles filled with $240 \mathrm{~g}$ of sawdust, supplemented with $20 \%$ wheat bran, $1 \%$ calcium carbonate and $1 \%$ gypsum $(\mathrm{w} / \mathrm{w})$. The sterilised sawdust mixture was then inoculated with $100 \times 15 \mathrm{~mm}$ mycelial agar discs and incubated at $25^{\circ} \mathrm{C}$ until the substrate was fully colonised (Wang et al., 2019).

The pre-wet sawdust substrate was mixed uniformly with wheat bran (20\%), $\mathrm{CaCO}_{3}(1 \%)$ and $\mathrm{CaSO}_{4}(1 \%)$. The water content of the sawdust mixture was adjusted to approximately $55-60 \%$. Each polythene bag (height: $30 \mathrm{~cm}$; diameter: $10 \mathrm{~cm}$ ) was filled with $0.5 \mathrm{~kg}$ of a sawdust-based substrate, sterilised $\left(121^{\circ} \mathrm{C}, 120 \mathrm{~min}\right)$ and then inoculated with $4 \mathrm{~g} \cdot \mathrm{bag}^{-1}$ of prepared spawn. The inoculated bags were kept in a spawn running room $\left(25 \pm 1^{\circ} \mathrm{C}\right.$ temperature and $80 \%$ relative humidity) under dark conditions. When the mycelium had fully colonised, the bags were shifted to the cropping room $\left(20 \pm 2{ }^{\circ} \mathrm{C}\right.$; relative humidity: $\left.>90 \%\right)$ to stimulate primordia formation. When the fruiting bodies were fully grown, they were then harvested for further analysis with clean hands by the twisting method to show the waveform margin (Liang et al., 2019).

\section{Preparation of methanolic extract}

Samples (400 g) of fresh fruiting bodies for each mushroom strain were dried at room temperature, followed by grinding to a fine powder. Twenty grams of the dried material was loaded into a Soxhlet apparatus and extracted in methanol $(80 \%)$ for $48 \mathrm{~h}$ at $30^{\circ} \mathrm{C}$. The methanolic extracts were then filtered through Whatman No. 4 paper and concentrated using a rotary evaporator at $36^{\circ} \mathrm{C}$ to dryness. The dried extracts were re-dissolved in $80 \%$ methanol at a concentration of $5 \mathrm{mg} \cdot \mathrm{mL}^{-1}$ and stored in the dark at $4^{\circ} \mathrm{C}$ for further use.

\section{Total phenolic content}

The total phenolic content (TPC) of the mushroom methanolic extracts was measured by the colourimetric assay (Chowdhury et al., 2015). In brief, $0.5 \mathrm{~mL}$ mushroom sample extract was mixed with $0.5 \mathrm{~mL}$ phenol reagent (Folin and Ciocalteu). After $5 \mathrm{~min}, 0.5 \mathrm{~mL}$ of sodium carbonate (14\%) was added to the mixture and adjusted to $5 \mathrm{~mL}$ with sterilised distilled water. The

Table 1. List of Auricularia cornea strains used in this study.

\begin{tabular}{llllc}
\hline $\begin{array}{l}\text { Original } \\
\text { reference }\end{array}$ & Strain name & Origin & Colour & Strain type \\
\hline Ac1 & WMAC001 & $\begin{array}{l}\text { Mushroom Breeding and Genetics Laboratory, Jilin Agricultural } \\
\text { University, Changchun, P. R. China }\end{array}$ & White & Commercial \\
Ac15 & WMAC012 & $\begin{array}{l}\text { Mushroom Breeding and Genetics Laboratory, Jilin Agricultural } \\
\text { University, Changchun, P. R. China }\end{array}$ & White & Cross breeding \\
Ac3 & JAUACP064 & $\begin{array}{l}\text { Mushroom Breeding and Genetics Laboratory, Jilin Agricultural } \\
\text { University, Changchun, P. R. China }\end{array}$ & Pink & Cross breeding \\
Ac24 & JAUACP001 & Dashushan Forest Park, Hefei City, Anhui Province, P. R. China & Brown & Wild domesticated \\
\hline
\end{tabular}



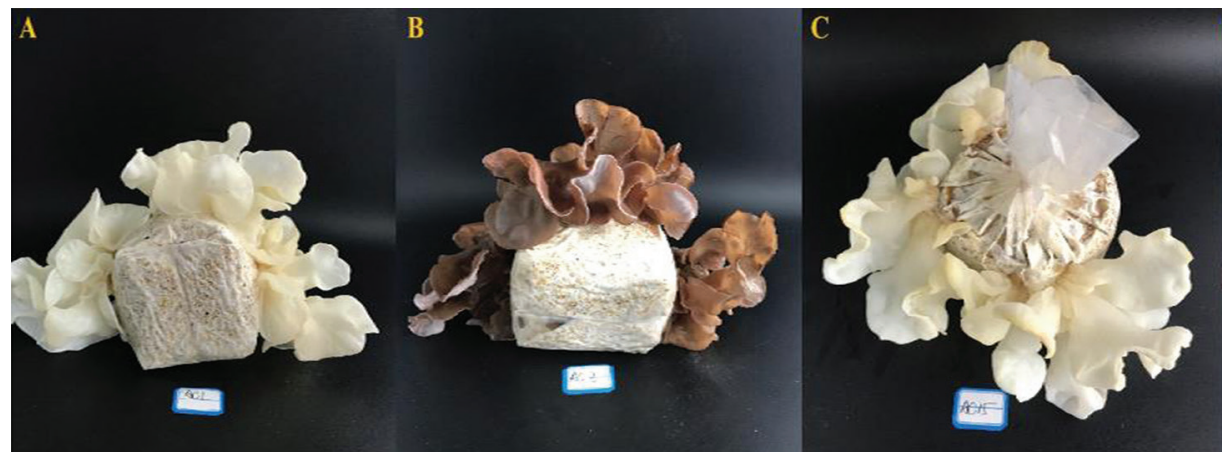

D D

Figure 1. Fruiting bodies of strains of Auricularia cornea: (A) Ac1, (B) Ac3, (C), Ac15 and (D) Ac24.

final solution was mixed properly, kept in the dark for $90 \mathrm{~min}$ for colour development and the absorbance was read spectrophotometrically at $750 \mathrm{~nm}$. Gallic acid was used as the standard, and the TPC was calculated as milligrams of gallic acid equivalents (GAE) per gram of the sample.

\section{Total flavonoid content}

The total flavonoid content (TFC) was estimated by the $\mathrm{AlCl}_{3}$ method (Zhang et al., 2015). Generally, $250 \mu \mathrm{L}$ of the methanolic extract of the mushrooms was mixed with $1.25 \mathrm{~mL}$ sterilised distilled water, followed by addition of $75 \mu \mathrm{L} \mathrm{NaNO}_{2}$. After 5 min of reaction, $150 \mu \mathrm{L}$ of $10 \%$ $\mathrm{AlCl}_{3}$ was added into the solution and $0.5 \mathrm{~mL}$ of $1 \mathrm{M}$ $\mathrm{NaOH}$ was added after some time. The total volume was adjusted up to $2.5 \mathrm{~mL}$ with sterilised distilled water, the solution was mixed well and the intensity of pink colour (at $510 \mathrm{~nm}$ ) was measured using a spectrophotometer. Catechin was used as the standard compound, and the TFC was stated as milligrams of catechin equivalents (CE) per gram of sample.

\section{Elemental composition}

Elemental composition of the powdered samples of the fruiting body of the $A$. cornea strains was determined by using scanning electron microscopy-energy-dispersive X-ray (SEM-EDX) analysis (Liu et al., 2015). The dried mushroom powder sample was placed on the cupper stub with the carbon tape and, then, a sputter coater (Hitachi E-1010) was used to coat the samples with gold for $20 \mathrm{~s}$ at $20 \mathrm{~mA}$. Afterwards, the mushroom samples were analysed by SEM (Hitachi S-4800 (Japan) and EDX ( Genesis-2000; Ametek, USA) at $8 \mathrm{~mm}$ working distance with $03 \mathrm{KV}$ and $\times 1.0 \mathrm{~K}$ magnification.

\section{Antioxidant activity}

\section{2,2-Diphenyl-1-picrylhydrazyl assay}

The 2,2-diphenyl-1-picrylhydrazyl (DPPH) assay of mushroom samples was performed according to a procedure described by Teoh et al. (2018). Accordingly, $200 \mu \mathrm{L}$ mushroom methanolic extract sample and control (methanol) were mixed with $2 \mathrm{~mL}$ DPPH $(0.2 \mathrm{~mm})$ solution. After $30 \mathrm{~min}$ incubation in the dark at $30^{\circ} \mathrm{C}$, the absorbance was measured at $517 \mathrm{~nm}$ using a 96-well microplate reader. The antioxidant activity was expressed as inhibition percentage $(I \%)$ and calculated by using the following equation:

$$
I \%==\left[\left(A_{\text {Control }}-A_{\text {Sample }}\right) / A_{\text {Control }}\right]^{\prime} \times 100
$$

DPPH inhibition (50\% inhibitory concentration) represents the $\mathrm{IC}_{50}$ value. It was calculated by constructing a curve between sample concentration versus inhibition percentage, and the results were presented as milligrams of sample per millilitre.

The $50 \%$ inhibitory concentration (halfmaximal inhibitory concentration or $\mathrm{IC}_{50}$ ) was the parameter used to compare the radical-scavenging activity. A lower $\mathrm{IC}_{50}$ means better radical scavenging activity.

\section{Ferric-reducing antioxidant power assay method for determining antioxidant capacity}

The ferric-reducing antioxidant power (FRAP) assay was used, according to Teoh et al. (2018). In brief, the methanol extract of the sample $(100 \mu \mathrm{L})$ of mushroom and distilled water (blank) were combined with $100 \mu \mathrm{L}$ of $0.2 \mathrm{M}$ phosphate buffer $(6.6 \mathrm{pH})$ and $100 \mu \mathrm{L}$ of $1 \%$ potassium ferricyanide. The mixture was incubated at $50^{\circ} \mathrm{C}$ for $30 \mathrm{~min}$, and $10 \%$ trichloroacetic acid solution was added after the mixture had cooled to room temperature. Afterwards, $125 \mu \mathrm{L}$ was transferred to 96-well plates from the upper surface and $20 \mu \mathrm{L}$ freshly prepared ferric chloride $(0.1 \%)$ was added. Finally, the absorbance value was measured at $620 \mathrm{~nm}$. Trolox was used as a standard, and the FRAP activity was expressed as milligrams of Trolox equivalents (TE) per gram of sample.

\section{Erythrocyte haemolysis analysis}

The erythrocyte haemolysis for A. cornea mushroom strains was assessed with certain modifications through the method of Liao et al. (2014) and Zhao et al. (2015). Briefly, erythrocytes were collected from the blood of healthy adult male volunteers aged $24-30$ years and body weight $64-71 \mathrm{~kg}$. Blood from the healthy male volunteers was collected by venipuncture in citrate-containing tubes. The obtained blood was centrifuged $(1,800 \mathrm{rpm}$, $10 \mathrm{~min}$ and $4^{\circ} \mathrm{C}$ ) and washed with phosphate-buffered saline (PBS) (20 mM and $\mathrm{pH} 7.4)$ thrice; then, $20 \%$ erythrocyte suspension was made with the same buffer 
solution. A $300 \mu \mathrm{L}$-aliquot of the $20 \%$ erythrocyte suspension was thoroughly mixed with an equal volume of PBS (absorbance A) or diosmetin (absorbance B) at various concentrations. The resultant solution was stored for $20 \mathrm{~min}$ at $37^{\circ} \mathrm{C}$ with continuous shaking at $60 \mathrm{rpm}$, and $600 \mu \mathrm{L}$ of 2,2'-azobis (2-amidinopropane) di-hydrochloride (AAPH) was added and stored for $2 \mathrm{~h}$ at the same temperature. The reaction solution was diluted with $12 \mathrm{~mL}$ PBS and centrifuged $(1,800 \mathrm{rpm}$, $10 \mathrm{~min}$ and $4^{\circ} \mathrm{C}$ ) before measuring the absorbance at $540 \mathrm{~nm}$. To obtain complete haemolysis, $8 \mathrm{~mL}$ of sterilised water was supplemented to the mixture, which was then centrifuged at $1,200 \mathrm{rpm}$ for $10 \mathrm{~min}$ at $4^{\circ} \mathrm{C}$, and the absorbance of the supernatant was measured at $540 \mathrm{~nm}$. The percentage of haemolysis inhibition was calculated as follows:

$$
\% \text { Haemolysis inhibition }==(1-A / B)^{\prime} \times 100 \%
$$

\section{Mineral quantification}

Minerals present in the $A$. cornea mushroom strains were quantified according to the methods used by Khan et al. (2019). The fruiting body samples were ovendried at $35^{\circ} \mathrm{C}$ for $24 \mathrm{~h}$ and made powder to pass through $1 \mathrm{~mm}$ sieve. To quantify mineral content in samples, $1 \mathrm{~g}$ mushroom from each sample was weighed. Afterwards, using the "wet" method mixture of nitric and perchloric acids (3:1) for digestion. At the end, solution was used for quantification of $\mathrm{Zn}, \mathrm{Cu}, \mathrm{Mn}$, and $\mathrm{Fe}$ by atomic absorption spectrometer.

\section{Molecular structure}

The molecular spectra of the fruiting bodies from various strains of $A$. cornea were obtained using Fouriertransform infrared (FTIR) spectroscopy (Vertex-70; Bruker). Ground (1 mg) samples were mixed with $100 \mathrm{mg}$ potassium bromide powder and pressed into tablet-shaped pellets under pressure, and the spectra were recorded at a frequency range of 500-4,000 $\mathrm{cm}^{-1}$ (Idrees et al., 2019).

\section{Statistical analysis}

The data were analysed using the well-known statistical method: Fisher's analysis of variance (ANOVA), and the treatment means were compared by using the least significant difference (LSD) test at the 5\% probability level.

\section{RESULTS AND DISCUSSION}

\section{Cultivation experiment}

Significant differences were noticed among the strains of A. cornea based on mycelium growth (days), pinhead's initiation (days), completion of mycelium growth (days), completion of formation of fruit bodies (days), yield, dry matter contents and biological efficiency (BE) (Table 2). The maximum mycelium growth per day was recorded for Ac3 $(2.09 \mathrm{~mm})$, followed by Ac1 $(1.98 \mathrm{~mm})$, Ac24 $(1.96 \mathrm{~mm})$ and Ac15 $(1.24 \mathrm{~mm})$. For complete mycelium colonisation of the substrate, a minimum number of days was noticed for Ac3 and Ac24 (50 days), followed by Ac1 (51 days) and Ac15 (75 days). Primordia formation was observed at the second week after the completion of colonisation of the mycelium bags. In general, the shortest time for completion of formation of fruit bodies was observed for wild strain Ac24 (91 days), followed by Ac3 (99 days), Ac1 (101 days) and Ac15 (115 days).

\section{Yield, dry matter content and BE}

Based on the weight of the fresh fruiting bodies of the A. cornea strains, the maximum yield was obtained from the commercial strain Ac1 (237.10 g), followed by Ac3 (224.47 g), Ac15 (158 g) and Ac24 (132.37 g), as shown in Table 2. According to our observations, the dry matter contents of the freshly harvested fruiting bodies of the A. cornea strains ranged from $11.56 \%$ to $18.15 \%$. The Ac15 and Ac24 strains possessed the maximum dry matter content $(18.15 \%$ and $17.42 \%$, respectively), while Ac1 and Ac3 exhibited the minimum dry matter content (11.56\% and $12.60 \%$, respectively). The $\mathrm{BE}$ is the ratio of the weight of the fresh fruiting body per dry weight of substrate, expressed as a percentage. Hence, the $\mathrm{BE}$ range of $A$. cornea strains was $52.94-94.84 \%$, with significant differences among the $A$. cornea strains (Table 2) (Wu et al., 2017).

\section{Estimation of phenolic and flavonoid contents}

The TPC in the fruiting bodies of $A$. cornea ranged from 8.76 to $20.10 \mathrm{mg} \mathrm{GAE} \cdot \mathrm{g}^{-1}$ of fruiting body (Figure 2). The wild A. cornea strain Ac24 presented the maximum TPC $\left(20.10 \mathrm{mg} \mathrm{GAE} \cdot \mathrm{g}^{-1}\right)$, followed by commercial Ac3 $\left(17.23 \mathrm{mg} \mathrm{GAE} \cdot \mathrm{g}^{-1}\right)$ and $\mathrm{Ac} 15\left(12.53 \mathrm{mg} \mathrm{GAE} \cdot \mathrm{g}^{-1}\right)$, while minimum TPC was observed in commercial

Table 2. Mycelium growth per day, pinhead initiation days, number of days for completion of formation of mycelium and fruiting bodies, yield, dry matter and biological efficiency of Auricularia cornea strains.

\begin{tabular}{lccccccc}
\hline Strains & $\begin{array}{c}\text { Mycelium } \\
\text { growth per day } \\
(\mathrm{mm})\end{array}$ & $\begin{array}{c}\text { Completion } \\
\text { of mycelium } \\
\text { formation } \\
\text { (days) }\end{array}$ & $\begin{array}{c}\text { Pinhead } \\
\text { initiation } \\
\text { (days) }\end{array}$ & $\begin{array}{c}\text { Completion of } \\
\text { formation of } \\
\text { fruiting bodies } \\
\text { (days) }\end{array}$ & Yield (g) & $\begin{array}{c}\text { Dry matter } \\
\text { contents (\%) }\end{array}$ & $\begin{array}{c}\text { Biological } \\
\text { efficiency (\%) }\end{array}$ \\
\hline Ac1 & $1.98 \pm 0.09 \mathrm{~b}$ & $51 \pm 2 \mathrm{~b}$ & $11 \pm 1 \mathrm{~b}$ & $101 \pm 3 \mathrm{~b}$ & $237.10 \pm 28 \mathrm{a}$ & $11.56 \pm 0.91 \mathrm{c}$ & $94.84 \pm 11 \mathrm{a}$ \\
Ac15 & $1.24 \pm 0.07 \mathrm{~d}$ & $75 \pm 3 \mathrm{a}$ & $10 \pm 1 \mathrm{c}$ & $115 \pm 2 \mathrm{a}$ & $158.00 \pm 03 \mathrm{~b}$ & $18.15 \pm 2.00 \mathrm{a}$ & $63.20 \pm 1 \mathrm{~b}$ \\
Ac3 & $2.09 \pm 0.04 \mathrm{a}$ & $50 \pm 1 \mathrm{c}$ & $14 \pm 1 \mathrm{a}$ & $99 \pm 3 \mathrm{~b}$ & $224.47 \pm 10 \mathrm{a}$ & $12.60 \pm 0.22 \mathrm{bc}$ & $89.78 \pm 4 \mathrm{a}$ \\
Ac24 & $1.96 \pm 0.06 \mathrm{c}$ & $50 \pm 2 \mathrm{c}$ & $11 \pm 1 \mathrm{~b}$ & $91 \pm 3 \mathrm{c}$ & $132.37 \pm 34 \mathrm{~b}$ & $17.42 \pm 4.03 \mathrm{ab}$ & $52.94 \pm 14 \mathrm{~b}$ \\
\hline
\end{tabular}

Values with no letter in common in each column are significantly different $(p<0.05)$ (means $\pm \mathrm{SD}, n=3$ ). 
Ac1 (8.76 mg GAE). The TFC of $A$. cornea strains ranged from 10.37 to $35.13 \mathrm{mg} \mathrm{CE} \cdot \mathrm{g}^{-1}$ (Figure 2). The highest TFC was observed in the commercial strain Ac1 (35.13 $\left.\mathrm{mg} \mathrm{CE} \cdot \mathrm{g}^{-1}\right)$, followed by wild Ac24 (29.04 mg $\left.\mathrm{CE} \cdot \mathrm{g}^{-1}\right)$ and the commercial strain Ac15 (25.14 mg $\left.\mathrm{CE} \cdot \mathrm{g}^{-1}\right)$. The lowest TFC was found in commercial A. cornea strain Ac3 $\left(10.37 \mathrm{mg} \mathrm{CE} \cdot \mathrm{g}^{-1}\right)$.

The TPC of $A$. cornea extracts was estimated by the Folin-Ciocalteu method, and gallic acid was used as the standard compound; the results are expressed as milligrams per gram GAE. Mushrooms contain a variety of secondary metabolites, including various kinds of phenolic compounds that have been shown to act as antioxidants. The identification and evaluation of the phenolic compounds in mushrooms are of great importance, both in their nutritional as well as functional characterisation (Ghahremani-Majd and Dashti, 2015). Phenolics are secondary metabolites commonly found in plants and fungi, reported to exert multiple biological effects, including medicinal and antioxidant activities (Dimitrios, 2006; Kim et al., 2008). Our results of the phenolic contents are consistent with the findings of Teoh et al. (2018), who observed quantities of phenolic substances in $A$. polytricha by the Folin-Ciocalteu method (Teoh et al., 2018).

\section{Estimation of elemental composition}

The EDX spectra revealed the presence of carbon, nitrogen, iron, zinc, sodium, magnesium, phosphorus, potassium and calcium in A. cornea strains (Figure 3). A higher level of nitrogen, iron and phosphorus, as well as a minimum level of calcium, was present in wild strain
Ac24 (13.40\%, 2.58\%, 1.27\% and $0.16 \%$, respectively). In comparison, the commercial strain Ac3 contained a maximum level of sodium $(0.04 \%)$ and calcium $(0.78 \%)$ and a minimum level of carbon (50.99\%). In addition, Ac1 strain contained high level of carbon (59\%) and magnesium $(0.22 \%)$, while another commercial strain Ac15 contained the maximum percentage of zinc $(0.46 \%)$ and potassium $(2.30 \%)$ and a minimum level of phosphorous $(0.38 \%)$ and nitrogen $(2.77 \%)$ (Table 3).

The elemental compositions of Lentinula edodes and Pleurotus cornucopiae var. citrinopileatus mushrooms were studied by Owaid et al. in different studies by SEM-EDX (Owaid et al., 2017, 2019), and they reported the presence of potassium, calcium, phosphorous and magnesium, with higher levels of oxygen and carbon. Our SEM-EDX findings of the elemental composition of various strains of $A$. cornea are in accordance with the results of Owaid et al. (2019). Apart from phosphorous, potassium, iron, calcium, zinc and magnesium, we noticed high percentage of oxygen, carbon, and nitrogen in all the strains.

\section{Estimation of mineral contents}

Table 4 indicates the mineral contents of the fruiting bodies of different strains of $A$. cornea. The copper and manganese contents of $A$. cornea ranged from 1.2 to $7.2 \mathrm{mg} \cdot \mathrm{kg}^{-1}$ and 371 to $788 \mathrm{mg} \cdot \mathrm{kg}^{-1}$, respectively. The maximum copper content was noticed in the commercial strain Ac1 $\left(7.2 \mathrm{mg} \cdot \mathrm{kg}^{-1}\right)$, followed by Ac3 (4.2 $\left.\mathrm{mg} \cdot \mathrm{kg}^{-1}\right)$ and Ac15 $\left(2.4 \mathrm{mg} \cdot \mathrm{kg}^{-1}\right)$, while minimum copper content was observed in

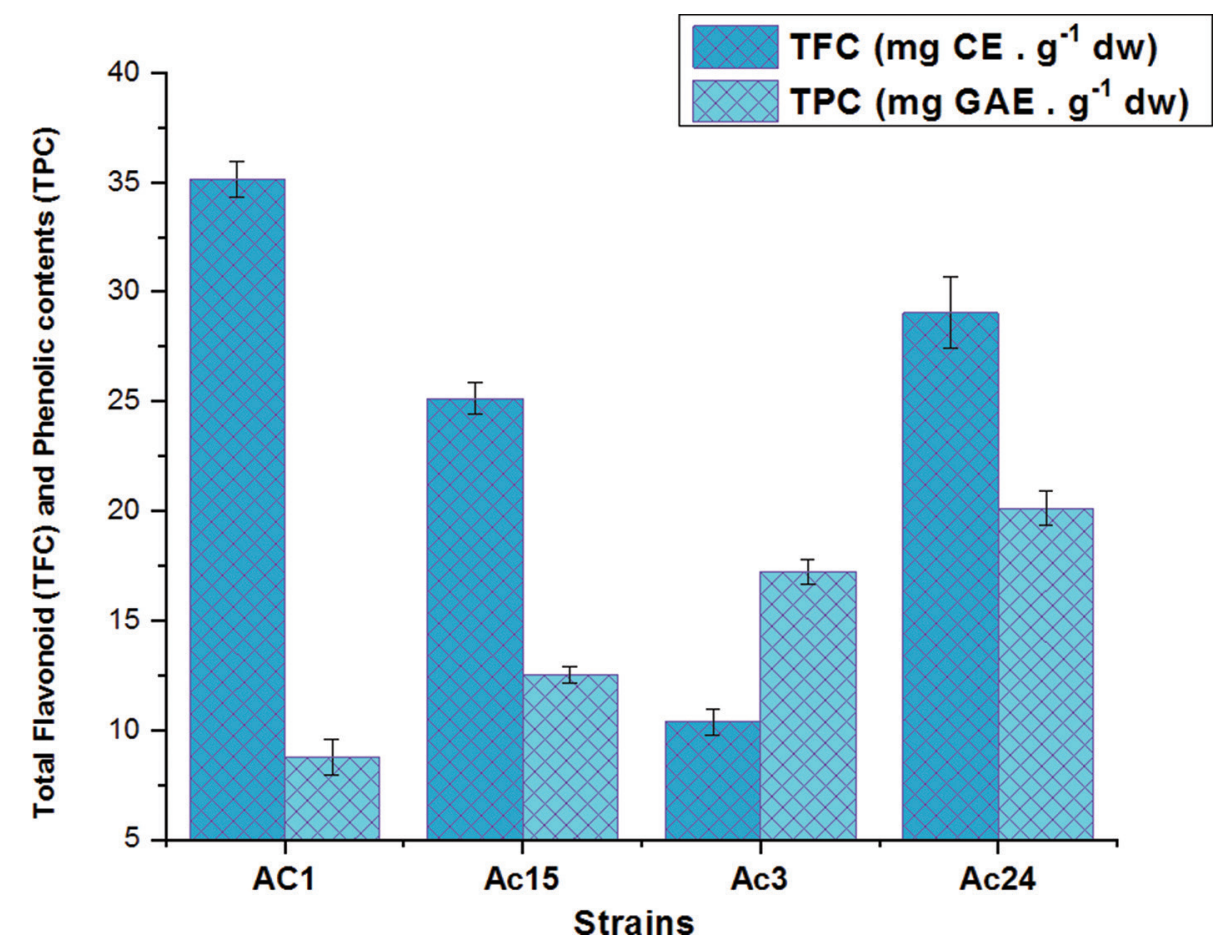

Figure 2. Total flavonoid content (TFC) and total phenolic content (TPC) of the four Auricularia cornea strains. dw, dry weight. 
the wild strain Ac24 (1.2 mg $\left.\cdot \mathrm{kg}^{-1}\right)$. A significant difference was observed in the manganese content of the $A$. cornea strains; the maximum manganese content was obtained from the commercial strain Ac3 $\left(788 \mathrm{mg} \cdot \mathrm{kg}^{-1}\right)$, followed by Ac1 (486 mg $\left.\cdot \mathrm{kg}^{-1}\right)$ and Ac15 (381 $\left.\mathrm{mg} \cdot \mathrm{kg}^{-1}\right)$, while the lowest was noticed in the wild strain Ac24 (371 mg $\cdot \mathrm{kg}^{-1}$ ). Among the various strains of $A$. cornea, the highest zinc contents were obtained from the commercial strain Ac1 $\left(310 \mathrm{mg} \cdot \mathrm{kg}^{-1}\right)$, followed by Ac3 (291 $\left.\mathrm{mg} \cdot \mathrm{kg}^{-1}\right)$, while the highest iron contents were noticed in the wild strain Ac24 (310 mg $\left.\cdot \mathrm{kg}^{-1}\right)$, followed by the commercial strain Ac15 $\left(275 \mathrm{mg} \cdot \mathrm{kg}^{-1}\right)$. On the contrary, the zinc contents were the lowest in the commercial strain Ac15 (291 mg $\left.\cdot \mathrm{kg}^{-1}\right)$, while the iron contents were the lowest in the commercial strain Ac3 $\left(77 \mathrm{mg} \cdot \mathrm{kg}^{-1}\right)$.

In general, zinc and iron contents were higher in A. cornea; mushrooms are good natural accumulators of zinc and iron, which are biologically very important to the human body. Our results are in line with the findings

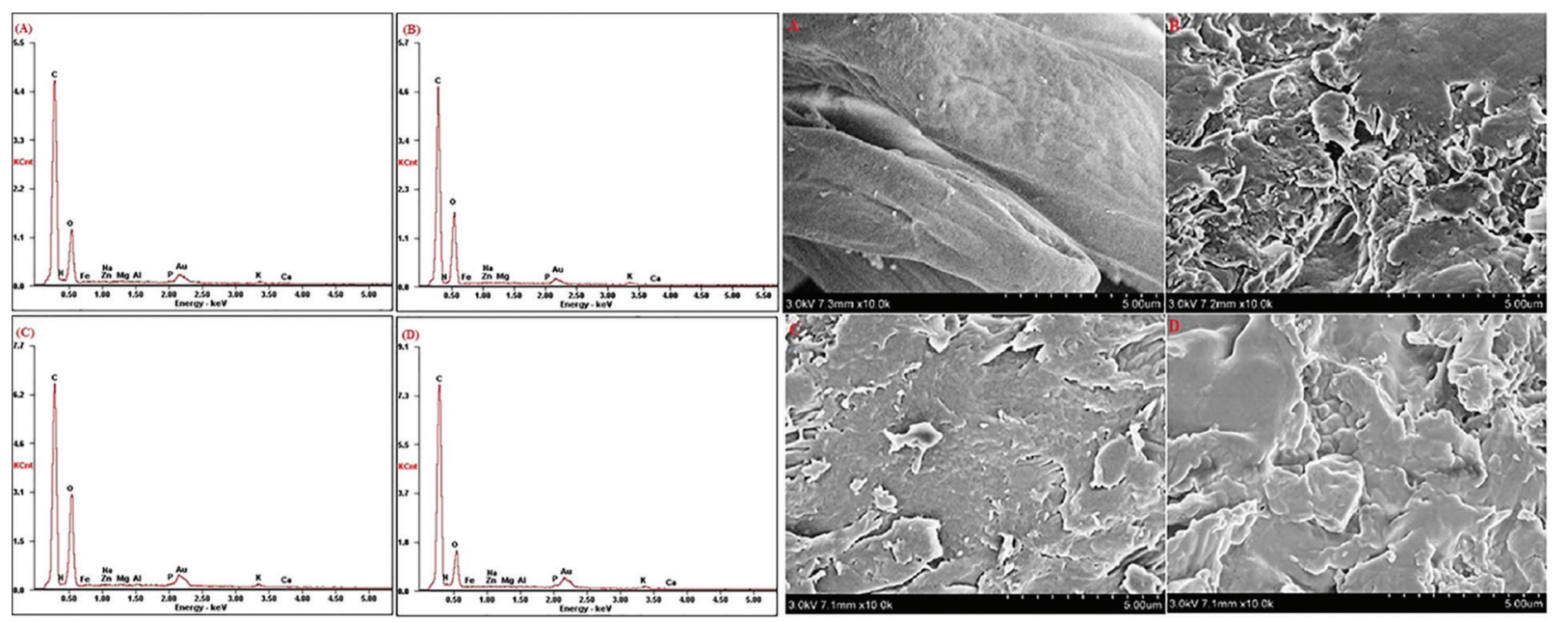

Figure 3. EDX spectra and SEM images of the fruiting bodies of various strains of Auricularia cornea (A) Ac1, (B) Ac15, (C), Ac3 and (D) Ac24. EDX, energy-dispersive X-ray; SEM, scanning electron microscopy.

Table 3. Average relative values (\% weight) for the elemental composition of Auricularia cornea strains.

\begin{tabular}{lcccc}
\hline Element (\%) & Ac1 & Ac15 & Ac3 & Ac24 \\
\hline $\mathrm{C}$ & $59.00 \pm 0.864 \mathrm{a}$ & $54.62 \pm 0.453 \mathrm{c}$ & $50.99 \pm 0.601 \mathrm{~d}$ & $57.42 \pm 0.148 \mathrm{~b}$ \\
$\mathrm{~N}$ & $5.21 \pm 0.209 \mathrm{~b}$ & $2.77 \pm 0.125 \mathrm{~d}$ & $3.55 \pm 0.229 \mathrm{c}$ & $13.40 \pm 0.075 \mathrm{a}$ \\
$\mathrm{O}$ & $30.23 \pm 0.864 \mathrm{c}$ & $36.89 \pm 0.453 \mathrm{~b}$ & $38.96 \pm 0.601 \mathrm{a}$ & $22.82 \pm 0.148 \mathrm{~d}$ \\
$\mathrm{Fe}$ & $2.27 \pm 0.249 \mathrm{ab}$ & $2.05 \pm 0.033 \mathrm{~b}$ & $2.05 \pm 0.123 \mathrm{~b}$ & $2.51 \pm 0.082 \mathrm{a}$ \\
$\mathrm{Zn}$ & $0.18 \pm 0.012 \mathrm{c}$ & $0.46 \pm 0.056 \mathrm{a}$ & 0.00 & $0.36 \pm 0.056 \mathrm{~b}$ \\
$\mathrm{Na}$ & 0.00 & 0.00 & $0.04 \pm 0.008$ & 0.00 \\
$\mathrm{Mg}$ & $0.22 \pm 0.012 \mathrm{a}$ & $0.18 \pm 0.008 \mathrm{~b}$ & $0.13 \pm 0.021 \mathrm{c}$ & $0.09 \pm 0.012 \mathrm{~d}$ \\
$\mathrm{Al}$ & 0.00 & 0.00 & $0.24 \pm 0.026 \mathrm{a}$ & $0.05 \pm 0.005 \mathrm{~b}$ \\
$\mathrm{P}$ & $0.77 \pm 0.017 \mathrm{c}$ & $0.38 \pm 0.021 \mathrm{~d}$ & $0.97 \pm 0.017 \mathrm{~b}$ & $1.27 \pm 0.012 \mathrm{a}$ \\
$\mathrm{K}$ & $1.63 \pm 0.125 \mathrm{c}$ & $2.30 \pm 0.079 \mathrm{a}$ & $2.28 \pm 0.059 \mathrm{a}$ & $1.92 \pm 0.012 \mathrm{~b}$ \\
$\mathrm{Ca}$ & $0.49 \pm 0.125 \mathrm{~b}$ & $0.36 \pm 0.079 \mathrm{c}$ & $0.78 \pm 0.059 \mathrm{a}$ & $0.16 \pm 0.012 \mathrm{~d}$ \\
\hline
\end{tabular}

Values with no letter in common in each column are significantly different $(p<0.05)$ (means $\pm \mathrm{SD}, n=3$ ).

Table 4. Mineral contents of wild and cultivated Auricularia cornea strains.

\begin{tabular}{lcccc}
\hline Strains & Copper $\left(\mathrm{mg} \cdot \mathrm{kg}^{-1}\right)$ & Manganese $\left(\mathrm{mg} \cdot \mathrm{kg}^{-1}\right)$ & Zinc $\left(\mathrm{mg} \cdot \mathrm{kg}^{-1}\right)$ & $\operatorname{Iron}\left(\mathrm{mg} \cdot \mathrm{kg}^{-1}\right)$ \\
\hline Ac1 & $7.2 \pm 0.1 \mathrm{a}$ & $486 \pm 5 \mathrm{~b}$ & $310 \pm 13 \mathrm{a}$ & $229 \pm 5 \mathrm{c}$ \\
Ac15 & $2.4 \pm 0.2 \mathrm{c}$ & $380 \pm 7 \mathrm{c}$ & $291 \pm 21 \mathrm{c}$ & $275 \pm 16 \mathrm{~b}$ \\
Ac3 & $4.2 \pm 0.3 \mathrm{~b}$ & $788 \pm 19 \mathrm{a}$ & $215 \pm 12 \mathrm{ab}$ & $77 \pm 3 \mathrm{~d}$ \\
Ac24 & $1.2 \pm 0.2 \mathrm{~d}$ & $371 \pm 25 \mathrm{c}$ & $261 \pm 12 \mathrm{~b}$ & $310 \pm 6 \mathrm{a}$ \\
\hline
\end{tabular}

Values with no letter in common in each column are significantly different $(p<0.05)$ (means $\pm \mathrm{SD}, n=3)$. 
(A)

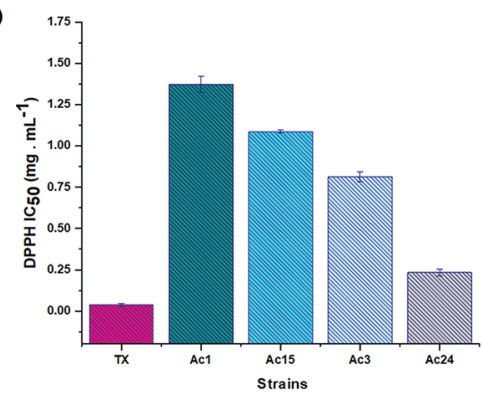

(B)

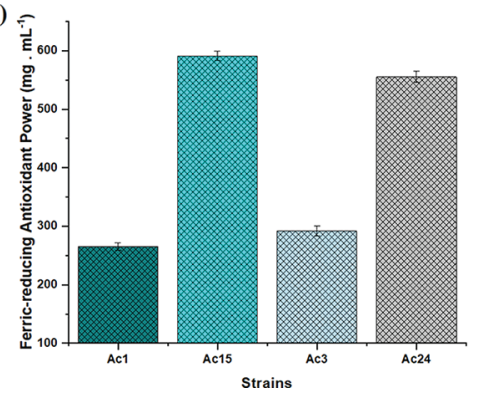

(C)

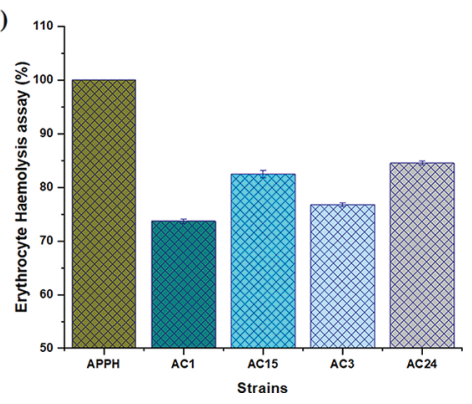

Figure 4. Assays of the extracts of the four strains of A. cornea: (A) DPPH radical-scavenging activity; (B) ferricreducing antioxidant power assay; and (C) erythrocyte haemolysis assay. DPPH, 2,2-diphenyl-1-picrylhydrazyl; $\mathrm{IC}_{50}, 50 \%$ inhibitory concentration.

of Wang et al. (2019), who studied the mineral contents in different $A$. cornea strains (Wang et al., 2019).

\section{Antioxidant activity of $A$. cornea}

The antioxidant activity of wild and commercial A. cornea strains was determined using the DPPH assay, as shown in Figure 4A. Significant variations were observed among the different strains studied.

The antioxidant activity, represented by the DPPHradical scavenging activity, of the $A$. cornea strains are presented as the $\mathrm{IC}_{50}$ in Figure 4A. The maximum DPPH radical-scavenging inhibition was noticed for the wild strain Ac24 $\left(\mathrm{IC}_{50}=0.2333 \mathrm{mg} \cdot \mathrm{mL}^{-1}\right)$, followed by the commercial strains $\mathrm{Ac} 3 \quad\left(\mathrm{IC}_{50}=\right.$ $\left.0.8133 \mathrm{mg} \cdot \mathrm{mL}^{-1}\right), \operatorname{Ac} 15\left(\mathrm{IC}_{50}=1.0867 \mathrm{mg} \cdot \mathrm{mL}^{-1}\right)$ and Ac1 $\left(\mathrm{IC}_{50}=1.3733 \mathrm{mg} \cdot \mathrm{mL}^{-1}\right)$. The capacity of Trolox $\left(\mathrm{IC}_{50}=0.0367 \mathrm{mg} \cdot \mathrm{mL}^{-1}\right)$ to scavenge DPPH radical was significantly higher than all the $A$. cornea strains.

DPPH radical is extensively used to evaluate the free radical-scavenging activity of natural products. The mechanism of scavenging DPPH radicals is that the natural compounds can transfer an electron or a hydrogen atom to DPPH. Based on this phenomenon, the DPPH radical-scavenging effect of $A$. cornea strains was determined. Our results agree with the studies of Teoh et al. (2018), who noticed that the radical-scavenging activity of the ethyl acetate extract of $A$. polytricha was better probably due to the higher phenolic contents (Teoh et al., 2018).

The antioxidant capacity of the wild and commercial strains of $A$. cornea, estimated by the FRAP assay, are presented in Figure 4B. The FRAP values of the free fraction in the four $A$. cornea strains ranged from 266 to $591 \mathrm{mg} \mathrm{TE} \cdot \mathrm{g}^{-1}$. The commercial strain Ac15 and the wild strain Ac24 showed the maximum antioxidant activity, while the commercial strains Ac3 and Acl exhibited a lower antioxidant activity in the FRAP assay.

The FRAP assay was used to evaluate the capacity of the antioxidant compound to reduce ferric ions $\left(\mathrm{Fe}^{3+}\right)$ to ferrous ions $\left(\mathrm{Fe}^{2+}\right)$ by electron transfer. An enhancement in the absorbance showed an increase in antioxidant activity. Similar results were obtained by Teoh et al. (2018), showing that $A$. polytricha has the ability to reduce ferric ions (Teoh et al., 2018).

\section{Erythrocyte haemolysis assay}

The oxidation-reducing potential of $A$. cornea strains, i.e. usefulness as an antioxidant, was further evaluated by the erythrocyte haemolysis assays (Figure 4C). All the wild and commercial strains of $A$. cornea attenuated the erythrocyte haemolysis induced by AAPH (Figure 4C). The maximum inhibition was observed in the wild strain Ac 24 (85\%), followed by the commercial strains Ac 15 (83\%), Ac 3 (77\%) and Ac 1 (74\%).

In erythrocyte haemolysis, alkyl radicals used as initiators are generated through decomposition by AAPH. Peroxyl radicals are produced in the presence of oxygen because of alkyl radicals, which leads to lipid peroxidation and the loss of membrane integrity, eventually leading to haemolysis. Plasma oxidation is a crucial factor that causes many life-threatening diseases. Oxidation of both low-density lipoprotein (LDL) and high-density lipoprotein (HDL) may lead to atherosclerosis and hypercholesterolemia, respectively. Copper induces the formation of dienes, which may increase over time, and it is known as a hallmark of lipid peroxidation (Liu et al., 2019). Therefore, haemolysis inhibition is an indirect way to attenuate the antioxidant ability of $A$. cornea.

\section{FTIR spectra of A. cornea strains}

FTIR spectra were obtained to investigate the functional groups of the active components of $A$. cornea mushroom strains, as well as to evaluate their bioactivity and structural characteristics. As shown in Figure 5, A. cornea strains revealed variation in the spectral region of the biochemical elements, i.e. carbohydrates, proteins and fatty acids. The FTIR spectra revealed the inclusive nutritional profile of the four strains of $A$. cornea mushroom $\left(4,000-500 \mathrm{~cm}^{-1}\right)$. The following important broad bands were identified in the $A$. cornea strains; commercial strain Acl contained 3,400 $\mathrm{cm}^{-1}(\mathrm{O}-\mathrm{H}$ and $\mathrm{C}-\mathrm{H}), 2,300 \mathrm{~cm}^{-1}(\mathrm{C}-\mathrm{H})$, and $1,630 \mathrm{~cm}^{-1}$ (proteins); commercial strain Ac15 showed 3,400 $\mathrm{cm}^{-1}(\mathrm{O}-\mathrm{H}$ and $\mathrm{C}-\mathrm{H}), 3,263 \mathrm{~cm}^{-1}(\mathrm{C}-\mathrm{H}), 2,855 \mathrm{~cm}^{-1}\left(\mathrm{CH}_{3}-\mathrm{CH}_{2}\right.$ lipids), 1,401 $\mathrm{cm}^{-1}$ (polysaccharides), $1,303 \mathrm{~cm}^{-1}(\mathrm{O}-\mathrm{H}$ bending polysaccharides, amide III), $1,025 \mathrm{~cm}^{-1}(\mathrm{C}-\mathrm{O}$ bond, $\beta(1 \rightarrow 3)$ glucan, cell wall, polysaccharide), $803 \mathrm{~cm}^{-1}$; commercial strain Ac3 showed 3,400 $\mathrm{cm}^{-1}$ 


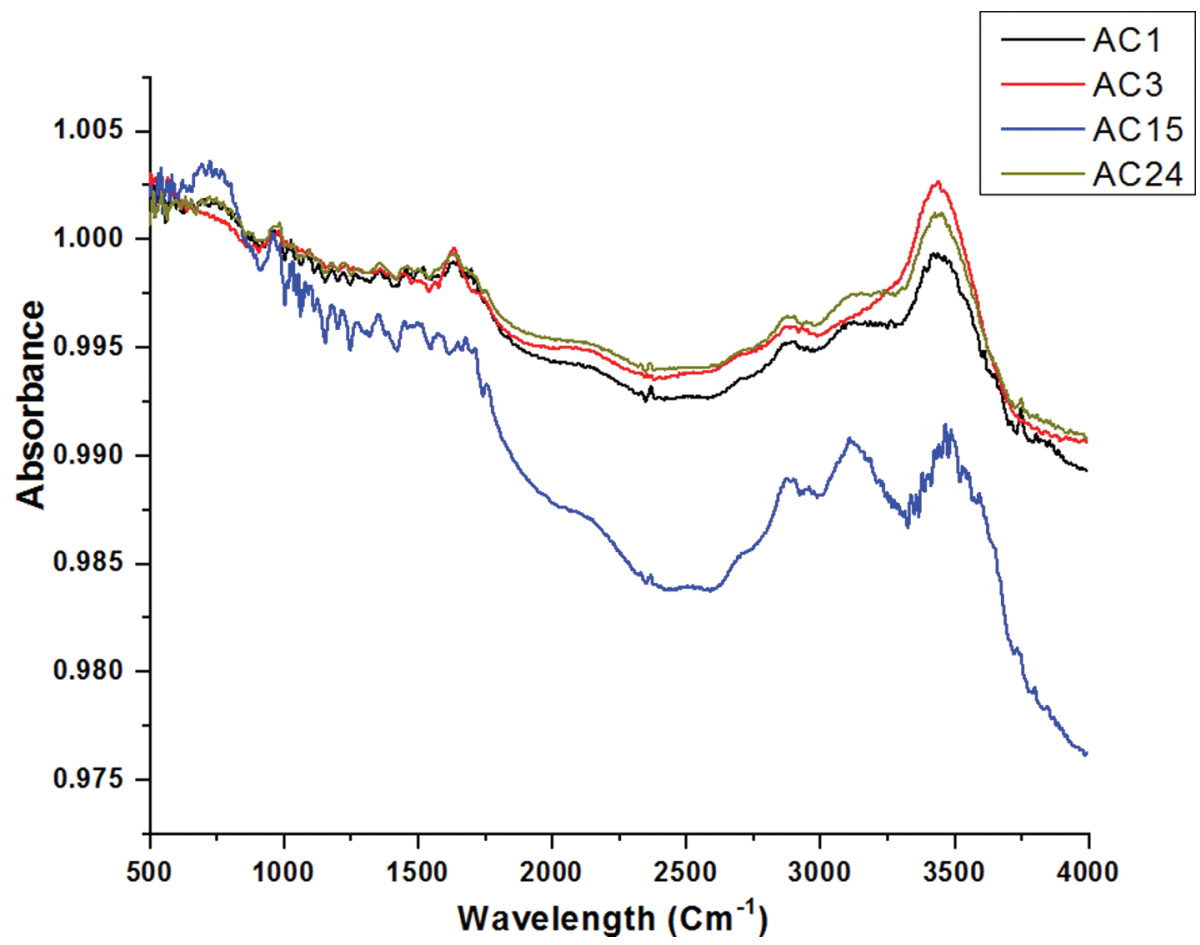

Figure 5. FTIR spectra of wild and cultivated strains of Auricularia cornea mushroom. FTIR, Fourier-transform infrared.

$(\mathrm{O}-\mathrm{H}$ and $\mathrm{C}-\mathrm{H}), 1,578 \mathrm{~cm}^{-1}$ (amide II, chitosan), $900 \mathrm{~cm}^{-1}$ ( $\alpha$ - and $\beta$-glycosides); and wild strain Ac24 contained $3,400 \mathrm{~cm}^{-1}(\mathrm{O}-\mathrm{H}$ and $\mathrm{C}-\mathrm{H}), 3,174 \mathrm{~cm}^{-1}(\mathrm{C}-\mathrm{H})$, $2,850 \mathrm{~cm}^{-1}\left(\mathrm{CH}_{3}-\mathrm{CH}_{2}\right.$ lipids $), 1,375 \mathrm{~cm}^{-1}$ ( $\beta$-glucan), $1,402 \mathrm{~cm}^{-1}$ (polysaccharides), $800 \mathrm{~cm}^{-1}(\alpha-$ and $\beta$-glycosides).

The occurrence of different functional groups of various compounds was detected by FTIR spectroscopy. Mushrooms are a hidden treasure of proteins, carbohydrates, as well as macro- and microelements, with minimum fat contents. Compositional analysis based on the functional group was well-elaborated by the peaks and spectra created by FTIR (Khan et al., 2019). Some early studies outlined the chemical characteristics for Agaricus bisporus and various strains of Pleurotus eryngii using peaks and functional groups detected by FTIR spectra (Idrees et al., 2019; Khan et al., 2019). One of the objectives of this study was to evaluate the differences between various strains of A. cornea mushroom, as FTIR is a non-destructive, quick and phase-interval method that is highly sensitive to dissimilarities occurring in the molecular structure and identifies a wide range of functional groups (Muhammad et al., 2019).

\section{CONCLUSIONS}

The current study showed that wild and commercial cultivated strains of $A$. cornea mushroom are a promising source of complete phenolic, flavonoid, FRAP, and erythrocyte haemolysis. The SEM-EDX and FTIR analyses verified the differences among the $A$. cornea strains based on different peaks at different positions. The present investigation on the methanolic extracts of $A$. cornea strains revealed the nutritional as well as therapeutic potential of $A$. cornea. In general, the wild domesticated brown strain Ac24, as a new germplasm of $A$. cornea, showed respectable potential for further development and investigation as a commercial strain, as well as to add genetic diversity in the commercial cultivation of mushroom.

\section{ACKNOWLEDGEMENT}

We are grateful to Yao Fangjie for making all the materials available and for critically reviewing the manuscript.

\section{FUNDING}

The research was supported by China Agriculture Research System (No. CARS-20).

\section{AUTHOR CONTRIBUTIONS}

Conceptualisation was done by F.Y. and Y.M.Z; methodology was by L.L. and M.F.; A.A.K. and W.J. worked on software and statistics; writing and preparation of the original draft was by A.A.K.; F.Y. and M.I. reviewed and edited the paper. P.W. helped in data collection. All authors read and approved the final manuscript.

\section{CONFLICT OF INTEREST}

The authors declare no conflict of interest. 


\section{REFERENCES}

Abd Razak, D. L., Abdullah, N., Johari, N. M. K., and Sabaratnam, V. (2013). Comparative study of mycelia growth and sporophore yield of Auricularia polytricha (Mont.) Sacc on selected palm oil wastes as fruiting substrate. Applied Microbiology and Biotechnology, 97(7), 3207-3213.

Arora, S., Goyal, S., Balani, J., and Tandon, S. (2013). Enhanced antiproliferative effects of aqueous extracts of some medicinal mushrooms on colon cancer cells. International Journal of Medicinal Mushrooms, 15(3), 301-314.

Cai, M., Lin, Y., Luo, Y. L., Liang, H. H., And Sun, P. (2015). Extraction, antimicrobial, and antioxidant activities of crude polysaccharides from the wood ear medicinal mushroom Auricularia auriculajudae (higher basidiomycetes). International Journal of Medicinal Mushrooms, 17(6), 591-600.

Chowdhury, M. M. H., Kubra, K., and Ahmed, S. R. (2015). Screening of antimicrobial, antioxidant properties and bioactive compounds of some edible mushrooms cultivated in Bangladesh. Annals of Clinical Microbiology and Antimicrobials, 14(1), 8. doi: 10.1186/s12941-015-0067-3.

Dai, Y., Li, X., Song, B., Lei, S., Yang, C., Zhang, X., AND LI, Y. (2019). Genomic analyses provide insights into the evolutionary history and genetic diversity of Auricularia species. Frontiers in Microbiology, 10, 2255. doi: 10.3389/fmicb.2019.02255.

Dimitrios, B. (2006). Sources of natural phenolic antioxidants. Trends in Food Science \& Technology, 17(9), 505-512.

Ghahremani-Majd, H., And Dashti, F. (2015). Chemical composition and antioxidant properties of cultivated button mushrooms (Agaricus bisporus). Horticulture, Environment, and Biotechnology, 56(3), 376-382.

Ghorai, S., Banik, S. P., Verma, D., Chowdhury, S., Mukherjee, S., and Khowala, S. (2009). Fungal biotechnology in food and feed processing. Food Research International, 42(5-6), 577-587.

Gupta, G., Sharma, R. K., Dahiya, R., Mishra, A., Timari, J., Sharma, G. N., And Dua, K. (2018). Aphrodisiac activity of an aqueous extract of wood ear mushroom, Auricularia polytricha (Heterobasidiomycetes), in male rats. International Journal of Medicinal Mushrooms, 20(1), 81-88.

Idrees, M., Yaqoob, S., Leo, S. F., Khan, A. A., Sun, L., YANG, Y., AND Li, Y. (2019). A comparison of the physical, chemical, and structural properties of wild and commercial strains of button mushroom, Agaricus bisporus (Agaricomycetes). International Journal of Medicinal Mushrooms, 21(6), 611-625.

Khan, A. A., Muhammad, M. J., Muhammad, I., Jan, I., SAmin, G., ZAhid, A., AND FANG, M. (2019). Modulation of agronomic and nutritional response of
Pleurotus eryngii strains by utilizing glycine betaine enriched cotton waste. Journal of the Science of Food and Agriculture, 99(15), 6911-6921.

Kim, M.-Y., Seguin, P., Ahn, J. K., Kim, J. J., Chun, S. C., Kim, E. H., AND PARK, Y. J. (2008). Phenolic compound concentration and antioxidant activities of edible and medicinal mushrooms from Korea. Journal of Agricultural and Food Chemistry, 56(16), 7265-7270.

Liang, C.H., Wu,C.Y.,Lu,P.L., Kuo, Y.C., AndLiang,Z.C. (2019). Biological efficiency and nutritional value of the culinary-medicinal mushroom Auricularia cultivated on a sawdust basal substrate supplement with different proportions of grass plants. Saudi Journal of Biological Sciences, 26(2), 263-269.

Liao, W., Ning, Z., Chen, L., Wei, Q., Yuan, E., Yang, J., AND REN, J. (2014). Intracellular antioxidant detoxifying effects of diosmetin on 2, 2-azobis (2-amidinopropane) dihydrochloride (AAPH)induced oxidative stress through inhibition of reactive oxygen species generation. Journal of Agricultural and Food Chemistry, 62(34), 8648-8654.

Liu, F., ZhaO, J. H., Gan, Z. L., And Ni, Y. Y. (2015). Comparison of membrane-bound and soluble polyphenol oxidase in Fuji apple (Malus domestica Borkh. cv. Red Fuji). Food Chemistry, 173, 86-91.

Liu, X., Sharma, R. K., Mishra, A., Chinnaboina, G. K., Gupta, G., And Singh, M. (2019). Role of aqueous extract of the wood ear mushroom, Auricularia polytricha (Agaricomycetes), in avoidance of haloperidol-induced catalepsy via oxidative stress in rats. International Journal of Medicinal Mushrooms, 21(4), 323-330.

Matkowski, A., Tasarz, P., and Szypula, E. (2008). Antioxidant activity of herb extracts from five medicinal plants from Lamiaceae, subfamily Lamioideae. Journal of Medicinal Plants Research, 2(11), 321-330.

Muhammad, I., Sossah, F. L., Yang, Y., Li, D., Li, S., FU, Y., AND Li, Y. (2019). Identification of resistance to cobweb disease caused by Cladobotryum mycophilum in wild and cultivated strains of Agaricus bisporus and screening for bioactive botanicals. RSC Advances, 9(26), 14758-14765.

Owaid, M. N., Al-SAeEdi, S. S. S., And Abed, I. A. (2017). Biosynthesis of gold nanoparticles using yellow oyster mushroom Pleurotus cornucopiae var. citrinopileatus. Environmental Nanotechnology, Monitoring \& Management, 8, 157-162.

Owaid, M. N., Rabeea, M. A., Aziz, A. A., Jameel, M. S., And Dheyab, M. A. (2019). Mushroom-assisted synthesis of triangle gold nanoparticles using the aqueous extract of fresh Lentinula edodes (shiitake), Omphalotaceae. Environmental Nanotechnology, Monitoring \& Management, 12, 100270, doi: 10.1016/j.enmm.2019.100270. 
SÁnchez, C. (2010). Cultivation of Pleurotus ostreatus and other edible mushrooms. Applied Microbiology and Biotechnology, 85(5), 1321-1337.

Sheu, F., Chien, P. J., Chien, A. L., Chen, Y. F., And Chin, K. L. (2004). Isolation and characterization of an immunomodulatory protein (APP) from the Jew's Ear mushroom Auricularia polytricha. Food Chemistry, 87(4), 593-600.

SonG, G., AND Du, Q. (2012). Structure characterization and antitumor activity of an $\alpha \quad \beta$-glucan polysaccharide from Auricularia polytricha. Food Research International, 45(1), 381-387.

Teoh, H. L., Ahmad, I. S., Johari, N. M. K., Aminudin, N., and Abdullah, N. (2018). Antioxidant properties and yield of wood ear mushroom, Auricularia polytricha (Agaricomycetes), cultivated on rubberwood sawdust. International Journal of Medicinal Mushrooms, 20(4), 369-380.

Wang, D., Jiang, X., Teng, S., Zhang, Y., Liu, Y., Li, X., AND LI, Y. (2019). The antidiabetic and antinephritic activities of Auricularia cornea (an albino mutant strain) via modulation of oxidative stress in the $\mathrm{db} /$ db mice. Frontiers in Immunology, 10, 1039, 10.3389/ fimmu.2019.01039.

Wang, P., YaO, F. J., Lu, L. X., FAnG, M., Zhang, Y. M., Khan, A. A., And Kiтамото, Y. (2019). Map-based cloning of genes encoding key enzymes for pigment synthesis in Auricularia cornea. Fungal Biology, 123(11), 843-853.

Wu, C. Y., Liang, C. H., Wu, K. J., Shin, H. D., AND Liang, Z. C. (2017). Effect of different proportions of agrowaste on cultivation yield and nutritional composition of the culinary-medicinal jelly mushroom Auricularia polytricha (higher basidiomycetes). International Journal of Medicinal Mushrooms, 19(4), 377-385.

YAnG, B. K., HA, J. Y., JeOnG, S. C., JeON, Y. J., RA, K. S., Das, S., AND Song, C. H. (2002). Hypolipidemic effect of an exo-biopolymer produced from submerged mycelial culture of Auricularia polytricha in rats. Biotechnology Letters, 24(16), 1319-1325.

YuAN, J. F., Zhang, Z. Q., FAN, Z. C., AND YANG, J. X. (2008). Antioxidant effects and cytotoxicity of three purified polysaccharides from Ligusticum chuanxiong Hort. Carbohydrate Polymers, 74(4), 822-827.

Zhang, N., Chen, H., Zhang, Y., Xing, L., Li, S., Wang, X., AND Sun, Z. (2015). Chemical composition and antioxidant properties of five edible Hymenomycetes mushrooms. International Journal of Food Science \& Technology, 50(2), 465-471.

Zhang, Y., YaO, A., And Song, K. (2016). Torrefaction of cultivation residue of Auricularia auricula-judae to obtain biochar with enhanced fuel properties. Bioresource Technology, 206, 211-216.

Zhao, L., Li, S., Zhao, L., Zhu, Y., and Hao, T. (2015). Antioxidant activities and major bioactive components of consecutive extracts from blue honeysuckle (Lonicera caerulea L.) cultivated in China. Journal of Food Biochemistry, 39(6), 653-662.

Received August 10, 2020; accepted September 18, 2020. 